\title{
Ellacuría y Romero: el sabio y el santo
}

Este mes de noviembre de 1994 se cumple un aniversario más —el quinto- de la muerte martirial de los seis sacerdotes jesuitas, de la humilde empleada y de su hija, asesinada en plena adolescencia. Hace ahora cinco años que nos los arrebataron y sentimos nuevamente la urgencia y la necesidad de revivir su memoria. Nos parece importante también, enfatizar la estrecha conexión entre el legado de nuestros mártires y el nuevo momento histórico que, en buena medida gracias a ellos, estamos hoy viviendo. Esto no siempre lo pudimos comprender con tanta claridad como ahora nos aparece, por lo que redactar estas reflexiones representa, para nosotros, una especie de confesión o de autocrítica.

Las dos figuras cimeras del cristianismo salvadoreño contemporáneo, Monseñor Romero e Ignacio Ellacuría, comparten el mérito de una muerte coherente con su vida. Se trata de una muerte que es multiplicadora de la obra fecunda que realizaron en vida. En ambos casos nos encontramos frente una muerte profética, premonitoria y denunciadora, que influyó significativamente en los acontecimientos posteriores que han acaecido en El Salvador. Las dos muertes, la del santo y la del sabio, marcan concretos momentos de inflexión en el proceso histórico salvadoreño. Con la muerte de Romero se desató la guerra; con la muerte de Ellacuría se desencadenó la paz.

El tiempo moldeó a Romero —l obispo conservador, el preferido por los oligarcas-, transformándolo íntima y profundamente en lo que constituyó una auténtica conversión. Romero se convir- tió así en el obispo del pueblo pobre, en el pastor de las mayorías populares, en la voz de los sin voz. Pero el tiempo, tercamente, no se dejaría moldear por Romero.

El trató de exorcizar a los agentes del mal con un llamado a sus corazones: "En nombre de Dios y de este sufrido pueblo, cuyos lamentos suben cada vez más tumultuosos hasta el cielo, les pido, les ruego, les ordeno, en el nombre de Dios, cesen la represión". Pero esos corazones humanos estaban secos, petrificados, muertos. Lejos de ablandarse, con el mensaje de amor cristiano se endurecían aún más. Para los verdugos, cada palabra de Monseñor Romero era una nueva prueba de su peligrosidad.

La verdad era demasiado subversiva, demasiado riesgosa, para un régimen cuya realidad era la falsedad. Le advirtieron, lo amenazaron, lo señalaron públicamente. Llegaron incluso a escenificar en los medios de comunicación el drama de una auténtica "crónica de la muerte anunciada". Pero no consiguieron intimidarlo. Como en la parábola del buen pastor, Romero se ofreció por sus ovejas y aceptó su destino. Intuyó que ésa era su misión y su mejor aporte: entregar su vida por su pueblo y por la paz.

Mas, sin embargo, su intención y voluntad nada podían frente a la implacable dialéctica del tiempo: su muerte precipitaría, en forma inmediata, la guerra. Esta estaba ya escrita en el signo de los tiempos y en el ánimo de los contendientes. Con su muerte ese signo resultó exacerbado. Se enardeció entoncés la indignación de las multitu- 


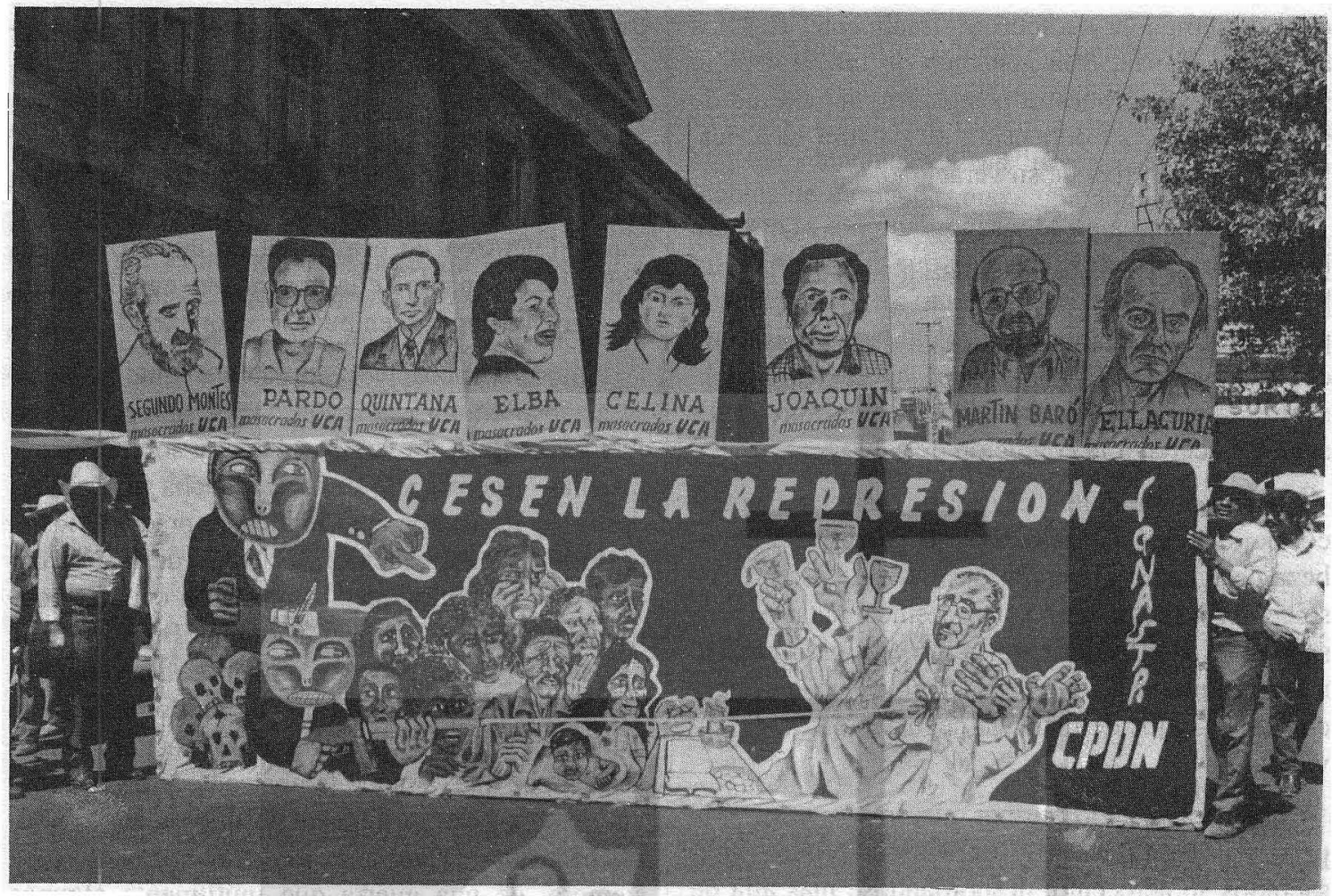

des, sobrecogidas por el horror del magnicidio, estremecidas por la crueldad implacable de los asesinos. De tal forma, la masa popular resultó arrastrada en el torbellino de la violencia. Con la muerte de Monseñor, la guerra se volvió en El Salvador una necesidad tan imperiosa e inevitable, como lo es un incendio en el bosque reseco al que una llama convierte súbitamente en una inmensa hoguera.

La palabra de amor y paz, de caridad y compasión, la voz de la razón, produjo, inconsciente e involuntariamente, su efecto contrario. La bondad, la santidad de Romero - venerada hoy por todo el continente, reconocida ahora incluso por la jerarquía eclesiástica conservadora-, no podía en su tiempo concreto, históricamente, otra cosa que desatar los demonios. Estos parecerían sepultar, en una incontenible oleada de odio, el mensaje de amor cristiano que el profeta de su pueblo se había esforzado en proclamar.

Sin embargo, su temporal fracaso aparecerá más tarde como su verdadero triunfo. De la atroz guerra pudo obtenerse finalmente una paz más cualificada y auténtica, más sólida y esperanzadora, que la que era posible alcanzar antes del conflicto. Del vendaval de odios desatados ha emergido al fin el consenso, el acuerdo, el abrazo de una mínima reconciliación. Ha surgido el reconocimiento hacia el otro y el reconocimiento de uno mismo en el otro, en tanto ambos se reconocen como partes de una entidad totalizadora y superior: la nación. En la definición del interés nacional, en la búsqueda del bien común, en el amor a la patria, ambos bandos se reconocen al fin. Pueden verse a sí mismos como patriotas y, al mismo tiempo, intuir en el otro su mismo patriotismo. Las dos partes reconocen la diferencia que los separa, pero también la identidad que los une, como salvadoreños, iniciándose la transformación, desde el odio fratricida, hacia la unidad en la nación y en el amor patrio.

Es así cómo la verdad de la palabra de Monseñor Romero es más comprensible en nuestros días, una vez más el tiempo hizo su trabajo. Su palabra ha pasado la prueba del tiempo: por la refutación a 
que el tiempo la sometió y, finalmente, tras los acuerdos de paz, a la negación de tal refutación. Adquiere así, en nuestra postguerra, la plenitud de su significado, su dimensión de palabra histórica, la prueba definitiva de su veracidad.

Ayer veíamos en Monseñor Romero al hombre bueno; hoy podemos entrever que fue también un hombre sabio. En su momento se nos apareció plenamente su dimensión de santidad, amplificada con su martirio. Corroboramos ahora también la sabiduría contenida en su vida y en su muerte. El santo se acercó a la condición de sabio.

Distinto y paralelo el destino, asimismo trágico, de los jesuitas asesinados. Disparando a la cabeza de Ignacio Ellacuría, destruyendo ese precioso cerebro, pretendieron sus asesinos matar el pensamiento pacificador. Quisieron, de esa manera, matar la negociación. Pero precipitaron el efecto contrario. Lejos de matar la negociación, le dieron vida.

No es exagerado afirmar que, tras su muerte, la presencia de Ellacuría y de sus compañeros masacrados se acrecentó, desbordándose más allá de las fronteras. En el mundo, fueron sacudidas las conciencias, transformando actitudes y motivando acciones internacionales prácticas, que hasta entonces habían faltado. Sus ideas demostraron estar más vivas que nunca. Su palabra, capturada para siempre en el papel, en el vídeo, en el casette o, simplemente, en la memoria, empezó a transformarse en actos, cobrando así auténtica vida.

De ahí la confirmación de su sabiduría, no solamente teórica, sino eminentemente práctica. De ahí su capacidad de contribuir a construir el futuro y de darle vida, más allá de su propia vida, cruelmente truncada. De ahí la necesidad del reconocimiento que hoy le dispensamos muchos que, en su momento, tal vez no lo escuchamos con la suficiente atención, pese a que tenía razón.

La sinrazón de la guerra -ese tiempo de locura, como lo ha calificado la Comisión de la verdad-, no dejaba mayor espacio a la auténtica razón, que planteaba dirimir las diferencias, debatiendo, concertando, razonando. Por más de una década, el tiempo impuso a los salvadoreños la pura razón negativa, la simple lógica de la des- trucción, el imperio del fanatismo y la intolerancia. Ciegos y sordos, incapaces de ver otras alternativas o de escuchar otras opciones, nos dejamos arrastrar por ese tiempo de furia. Para la mayoría, era ése tiempo de plantearse quién tiene la razón, no de preguntarse cuáles son las razones del contrario. La razón de esa forma unilateralizada excluía lo razonable, convirtiéndose en el fondo, para ambos bandos, en pura irracionalidad.

Sólo unas pocas voces, prácticamente aisladas, se alzaban contra esa razón de los tiempos, desafiando su signo. La voz de Ellacuría sobresalía entre ellas, a contrapelo de la avalancha histórica, a despecho de su aparente ineficacia práctica, insistentemente, tozudamente. El tiempo de la destrucción y sus terribles agentes ajustaron cuentas contra ella, acallándola para siempre. Pero esa voz cargada de razón consiguió a su vez su venganza contra el tiempo. Lo doblegó, lo domesticó, le cambió su signo. El país conseguiría así el milagro de una paz que, aunque tambaleante y frágil todavía, insegura como niño tierno que da sus primeros pasos, ha dejado atrás el cadáver, muerto para siempre, de una guerra que inútilmente algunos quisieran revivir.

La figura de Ellacuría nos aparece ahora agigantada, mostrando la que fue su real dimensión: el mayor intelectual al servicio de las mayorías populares, el pensador popular más importante de las últimas dos décadas, un auténtico "intelectual orgánico" del pueblo salvadoreño. Su obra debe ser estudiada con atención especial por la joven generación actual: ella es capaz de iluminar, desde su pasado, los oscuros desafíos del presente.

Al estudiar la obra de Ellacuría, a la par de su sabiduría, se encontrará una forma especial de ser bueno, una manera específica de santidad. No la santidad egoísta e inútil de la quietud, de la contemplación, del cultivo interior, sino aquella que se vierte al exterior. Es una bondad más difícil de reconocer: la del activista, la del hombre de acción, a quien no le alcanzan las horas del día y que termina la jomada aturdido por la fatiga, con la agenda del mañana cargada de nuevos sueños y nuevas esperanzas.

Por amor al hombre, por su especial cariño ha- 
cia las mayorías populares, Ellacuría, en vez de apartarse del mundo, de encerrarse cómodamente en la torre de marfil de lo académico o en la sosegada cotidianeidad del teórico puro, se zambulló en el frenético vaivén de una realidad nacional en plena ebullición. Buscó transformarla y, con ella, transformar asimismo al hombre. La fría sabiduría del pensador se humanizó y llenó de vida en ese contacto, en ese vivo compromiso. El sabio se acercó así a la condición de santo.
De esa forma podemos contemplar hermanados -en su vida y en su muerte- a estos dos mártires, Romero y Ellacuría, tan distintos y a la vez tan semejantes. Constituyen hoy símbolos vivientes de un pueblo que se ha abierto paso, a través de tiempos terribles, hasta alcanzar algo de la sabiduría y la santidad que ellos le supieron devolver en un recodo de la historia. Es éste un legado precioso de nuestros mártires, el cual debemos saber cuidar: nos hará falta en el próximo caminar.

R. R. 